\title{
Processes and Methods for Promoting Success in Engineering Projects
}

\author{
Hesham Ahmad \\ Editor \\ Editorial \\ Available online December 30, 2018
}

This issue of the Journal consists of five research articles. The results of these articles have a common objective to develop and encourage processes and methods important for the success of engineering projects. Although, there is no agreement in the literature on the factors that distinguish successful projects from failed ones, the success of projects can generally be estimated by the comparison of their performance against the design parameters (Gaddis, 1959; Pinto and Slevin, 1988).

It is noticeable that all of the five papers in this issue are dedicated to engineering project management. Three of the five researches are conducted in the field of the construction industry. The authors and co-authors of the papers belong to various regions over the world, but the importance of their research results is not constrained by the boundaries of their regions.

The first paper is authored by Z. Kahvandi et al. from MehrAlborz University (Tehran, Iran) and Abu Dhabi University (UAE). The paper contributes to the identification of the barriers to the implementation of Integrated Project Delivery (IPD). IPD is a recent comprehensive implementation system that plays an effective role in projects' improved efficiency. The barriers were extracted from 17 existing case studies. The results of the research create motivation for owners for implementing IPD in the construction industry, and help provide the context for required predictions.

The second paper is authored by L. Hoxha, and C. McMahan from Walden University (Minnesota, USA). This paper investigates the influence of the age of the project manager on the project success. A quantitative analysis of 108 project managers working in Albania or Kosovo, demonstrated that age did not significantly predict project success. The results are important to help reduce the age discrimination against project managers by increasing the awareness among employers.

The third paper is authored by R. Abdulrahman et al. from Ahmadu Bello University (Nigeria). According to the authors, the previous studies have only assessed risk associated with JV projects. In this study, the Risk Management Maturity (RMM) of construction organizations was assessed in Joint Venture (JV) projects. A survey was conducted using five maturity levels. Twenty-six dimensions categorized into four attributes were used to assess the Risk Management Capability (RMC). The results showed that construction organizations undertaking JV projects are at the "defined maturity level," which means they only practice informal risk management and use only qualitative risk assessment techniques. The authors recommended improving the current RMM level to the next maturity level (managed and optimised).

The fourth paper is authored by C. Ko and J. Kuo from National Pingtung University of Science and Technology (Taiwan). The paper presented an innovative approach for making enhancement to the traditional formwork design by using lean thinking. Building Information Modelling (BIM) was adopted to provide a visual communication platform for design team members. To establish organizational learning environment, the study used Industry Foundation Classes for sharing design artifacts, and design correctness to review and correct errors. Finally, the Lean Formwork Design Process was conceptualized using stock-flow diagrams, and validated for applicability using a real case. The new method proved its usefulness in enhancing design correctness, and saving manpower and operational time in formwork engineering.

The fifth paper is authored by J. Balakrishnan and C. H. Cheng from University of Calgary (Canada) and Logistics and Supply Chain Multitech R\&D Centre (Hong Kong). The paper investigates the role of knowledge intermediaries in the dissemination of a type of knowledge proposition in project and production management called "evangelical" proposition. The authors conducted a case study to examine the development of the Theory of Constraints (TOC) and Critical Chain Project Management (CCPM). The results showed that knowledge intermediaries will be better prepared to deal with similar innovations in a balanced manner.

In addition to the intensive literature review, the five papers included in this issue have also applied rich methodologies for the research investigation and innovation. It is obvious that the contents and results of the presented papers would be of great importance to people from the academia and the industry.

\section{References}

Gaddis, P. O. (1959). The project manager. Harvard Business Review, 37(3), 89-97.

Pinto, J. K. and Slevin, D. P. (1988). Project success: definitions and measurement techniques. Project Management Journal, 19(1), 67-72. 